\title{
An Experimental Study of Shower Spray Properties and Shower Comfort
}

\author{
Wing-Kwong CHAN \\ Department of Building Services Engineering, The Hong \\ Kong Polytechnic University, \\ Hong Kong, China \\ Yang ZHOU \\ Department of Building Services Engineering, The \\ Hong Kong Polytechnic University, \\ Hong Kong, China
}

\begin{abstract}
Shower comfort influences the adoption of water saving showerheads, and thus the implementation of sustainable water conservation programs. This study investigates the shower spray properties of 7 sampled showerheads experimentally and evaluates their relationships with user satisfaction according to shower comfort feedback. The feedback from 30 participants showed that spray force and water flow rate were the two most influential factors determining shower comfort. It was found that if either the spray spread angle (e.g. $17^{\circ}, 4^{\circ}$ ), spray coverage area (e.g. $0.122 \mathrm{~m}^{2}, 0.232 \mathrm{~m}^{2}$ ) or spray force (e.g. 1.67 N, $2.43 \mathrm{~N}$ ) was too large, the level of shower comfort would decrease. Moreover, shower comfort may be independent of spray velocity and flow rate.
\end{abstract}

Keywords-Showerhead; Shower spray properties; Shower comfort; Optimum flow rate.

\section{INTRODUCTION}

Improving shower water efficiency leads to energy savings and carbon emissions reduction. To encourage shower water conservation in Hong Kong, a voluntary Water Efficiency Labelling Scheme (WELS) on showers for bathing has been implemented by the Hong Kong Water Supplies Department (HKWSD) since 2009 [1]. A study by Okamoto et al. [2] reported that shower spray properties, including water distribution pattern, temperature drop and spray spread angle, influenced user satisfaction with showerheads. To efficiently promote the WELS rated showerheads in Hong Kong, a local study of shower comfort is necessary.

This study investigates the shower spray properties of 7 sampled shower heads experimentally and evaluates their relationships with user satisfaction according to shower comfort feedback.

\section{EXPERIMENTAL STUDY}

Fig. 1 shows a schematic diagram of the laboratory-made water circulation system used in the experiments. An electronic scale was placed underneath a showerhead to measure the force exerted by the spray on the body. The top

\author{
Ling-Tim WONG* \\ Department of Building Services Engineering, The Hong \\ Kong Polytechnic University, \\ Hong Kong, China \\ e-mail: beltw@polyu.edu.hk
}

Kwok-Wai MUI

Department of Building Services Engineering, The Hong Kong Polytechnic University, Hong Kong, China

of the scale was $0.4 \mathrm{~m}$ from the showerhead faceplate. The scale was replaced by an annular gauge when measuring water distribution patterns within the spray cross-section. As shown in Fig. 2, the annular gauge had four circles of graduated cylinders. A high speed camera was prepared for taking photos of the discharging showerheads. Fig. 3 exhibits the 7 showerheads sampled.

Based on the measurement method by the HKWSD [1], the flow rates of all showerheads were measured over an inlet pressure range of $0.5-2.5$ bar. The spray velocity, spray spread angle, spray coverage, force exerted by the spray on the body and water distribution pattern within the spray cross-section were measured at a pressure of 1 bar.

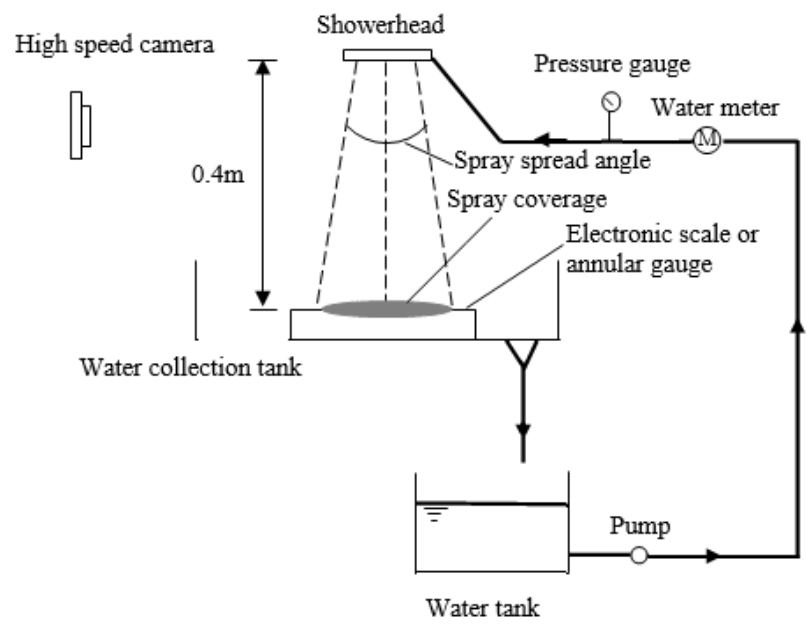

Figure 1. Schematic diagram of experimental setup.

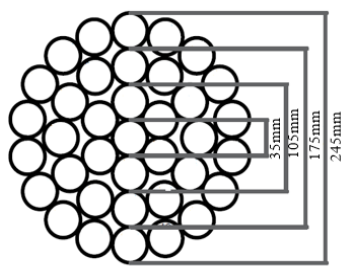

Figure 2. Annular gauge. 


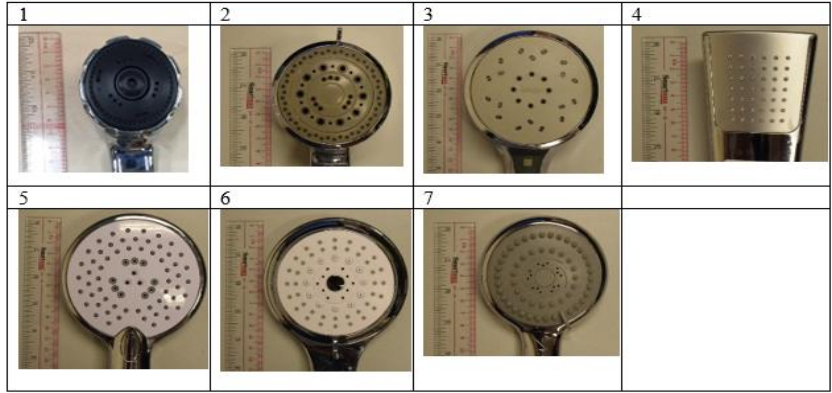

Figure 3. Showerheads sampled.

The spray velocity $\mathrm{v}_{\mathrm{s}}\left(\mathrm{m} \mathrm{s}^{-1}\right)$ at the location $20 \pm 5 \mathrm{~mm}$ underneath the showerhead can be obtained from a series of photos taken by the high speed camera. Similarly, the spray spread angle $\theta_{\mathrm{s}}\left({ }^{\circ}\right)$ can be determined by the photos.

The force exerted by the spray on the body Fs $(\mathrm{N})$ can be determined using the following formula, where $\mathrm{M}(\mathrm{kg})$ is the mass reading from the electronic scale when the showerhead is operating, $\mathrm{m}_{0}(\mathrm{~kg})$ is the mass of the water left on the electronic scale after showering, and $\mathrm{g}\left(\mathrm{m} \mathrm{s}^{-2}\right)$ is the gravitational acceleration,

$$
F_{s}=\left(M-m_{0}\right) g
$$

The shower head resistance factor $\mathrm{K}\left(\mathrm{kPa} \min ^{2} \mathrm{~L}^{-2}\right)$ is expressed by the following equation, where $\mathrm{P}(\mathrm{kPa})$ is the pressure loss and $\mathrm{Q}\left(\mathrm{L} \mathrm{min}^{-1}\right)$ is the water flow rate,

$$
K=\frac{P}{Q^{2}}
$$

\section{SubJeCtive ASSESSMENT}

A total of 30 Hong Kong residents were recruited in this study. They washed the back of their hands using the setup a s shown in Fig. 1 and their feedback on the sampled showerh eads was collected.

The optimum pressures of the sampled showerheads, i.e. the shower spray pressures that were most satisfying to the $p$ articipants, were determined. Participants' feedback on the $s$ pray properties, including water flow rate, spray angle, spray coverage and spray force, was evaluated using a four-point $\mathrm{s}$ emantic differential scale (' 1 ' indicates the most influential $\mathrm{f}$ actor and '4'indicates the least influential factor for shower c omfort). The showerheads sampled were ranked by the partic ipants based on shower comfort via a seven-point semantic d ifferential scale (' 1 ' indicates the most satisfactory showerhe ad and ' 7 ' indicates the least satisfactory showerhead).

\section{RESULTS AND DISCUSSION}

Table 1 summarizes the characteristics and spray properties of the 7 shower heads sampled.

The feedback results shows that spray force (average scale 1.5) was considered by the participants as the most influential factor determining shower comfort, followed by water flow rate (average scale 2.1).

Relationships between satisfaction ranking of the showerheads sampled and resistance factor K, spray spread angle, spray coverage, spray velocity, spray force and optimum flow rate are graphed in Fig. 4.

TABLE I. SUMMARY OF CHARACTERISTICS AND SPRAY PROPERTIES

\begin{tabular}{|c|c|c|c|c|c|c|c|c|}
\hline \multirow{2}{*}{\multicolumn{2}{|c|}{ Specification }} & \multicolumn{7}{|c|}{ Showerhead } \\
\hline & & \multirow{2}{*}{$\frac{1}{\text { Conventional }}$} & \multirow{2}{*}{\multicolumn{2}{|c|}{$\begin{array}{cc}2 & 3 \\
\text { Conventional Conventional }\end{array}$}} & \multirow{2}{*}{$\begin{array}{c}4 \\
\text { Aerating } \\
0.067(\mathrm{U})^{\circ}\end{array}$} & \multirow{2}{*}{$\frac{5}{\text { WELS }^{*}}$} & \multirow{2}{*}{$\frac{6}{6 \text { WELS" }}$} & \multirow{2}{*}{$\frac{7}{\text { WELS }}$} \\
\hline & Type & & & & & & & \\
\hline \multicolumn{2}{|c|}{ Showerhead diameter (m) } & 0.045 & 0.080 & 0.150 & $\begin{array}{l}0.057(\mathrm{~L})^{*} \\
0.067(\mathrm{H})^{*}\end{array}$ & 0.115 & 0.107 & 0.085 \\
\hline \multirow{4}{*}{\multicolumn{2}{|c|}{$\begin{array}{l}\text { Number of } 0.5 \mathrm{~mm} \text { nozzles } \\
\text { Number of } 1 \mathrm{~mm} \text { nozzles } \\
\text { Number of } 2 \mathrm{~mm} \text { nozzles } \\
\text { Number of } 3 \mathrm{~mm} \text { nozzles }\end{array}$}} & 0 & 48 & 0 & 0 & 59 & 0 & 52 \\
\hline & & 48 & 0 & 36 & 42 & 0 & 52 & 15 \\
\hline & & 9 & 19 & 8 & 0 & 9 & 10 & 0 \\
\hline & & 0 & 10 & 0 & 0 & 3 & 0 & 0 \\
\hline \multicolumn{2}{|c|}{$\begin{array}{l}\text { Ratio of total nozzle area to } \\
\text { showerhead faceplate area }\end{array}$} & 0.0415 & 0.0278 & 0.0030 & 0.0079 & 0.0059 & 0.0080 & 0.0039 \\
\hline \multicolumn{2}{|c|}{$\begin{array}{l}\text { Resistance factor } \mathrm{K} \\
\left(\mathrm{kPa} \min ^{2} \mathrm{~L}^{-2}\right)\end{array}$} & 1.90 & 1.82 & 0.19 & 0.63 & 16.50 & 11.99 & 3.36 \\
\hline \multicolumn{2}{|c|}{ Spray spread angle $\theta_{1}\left({ }^{\circ}\right)$} & 2 & 11 & 40 & 17 & 11 & 13 & 9 \\
\hline \multicolumn{2}{|c|}{ Spray coverage $\mathrm{A}_{4}\left(\mathrm{~m}^{2}\right) \times 10^{-2}$} & 0.56 & 1.64 & 12.20 & 2.35 & 23.20 & 2.36 & 1.50 \\
\hline \multicolumn{2}{|c|}{ Spray force $F_{1}(N)$} & 1.05 & 0.75 & 2.43 & 1.67 & 0.34 & 0.39 & 0.62 \\
\hline \multicolumn{2}{|c|}{ Spray velocity $v_{f}\left(\mathrm{~m} \mathrm{~s}^{-1}\right)^{*}$} & 0.66 & 0.78 & 0.72 & 0.43 & 0.18 & 0.27 & 0.24 \\
\hline \multirow{4}{*}{$\begin{array}{l}\text { Water } \\
\text { pattern }\end{array}$} & Circle $1(\%)$ & 6 & 23 & 15 & 8 & 4 & 1 & 17 \\
\hline & Circle $2(\%)$ & 28 & 61 & 52 & 21 & 39 & 62 & 28 \\
\hline & Circle $3(\%)$ & 36 & 14 & 24 & 35 & 42 & 37 & 51 \\
\hline & Circle 4(\%) & 30 & 1 & 9 & 36 & 15 & 0 & 5 \\
\hline
\end{tabular}
OF SHOWERHEADS SAMPLED.

Figure 4(a) shows that for resistance factor $\mathrm{K}$, either small values (e.g. $\leq 1.82 \mathrm{kPa} \min ^{2} \mathrm{~L}^{-2}$ ) or a large value (e.g. $16.50 \mathrm{kPa} \min ^{2} \mathrm{~L}^{-2}$ ) would decrease the level of shower comfort. According to Figure 4(b), shower comfort level would decrease when the spray spread angle was too large (e.g. $\left.17^{\circ}, 40^{\circ}\right)$. Similarly, when the spray coverage area (e.g. $0.122 \mathrm{~m}^{2}, 0.232 \mathrm{~m}^{2}$ ) and spray force (e.g. $1.67 \mathrm{~N}, 2.43 \mathrm{~N}$ ) were too large, the level of shower comfort would decrease, as shown in Figures4(c) and 4(d). The inconspicuous relationships presented in Figures 4 (e) and 4 (f) indicate that shower comfort may be independent of spray velocity and flow rate.

\section{CONCLUSION}

A voluntary Water Efficiency Labelling Scheme (WELS) on showers for bathing has been implemented by the Hong Kong Government since 2009for sustainable water use. This study experimentally examined the shower spray properties of 7 sampled shower heads. The feedback from 30 participants showed that spray force and water flow rate were the two most influential factors determining shower comfort. It was found that if either the spray spread angle (e.g. $17^{\circ}, 40^{\circ}$ ), spray coverage area (e.g. $0.122 \mathrm{~m}^{2}, 0.232 \mathrm{~m}^{2}$ ) or spray force (e.g. $1.67 \mathrm{~N}, 2.43 \mathrm{~N}$ ) was too large, the level of shower comfort would decrease. Furthermore, shower comfort may be independent of spray velocity and flow rate.

\section{ACKNOWLEDGMENT}

The work described in this paper was partially supported by a grant from the Hong Kong Research Grants Council (Poly U 5272/13E) and by 3 different grants from The Hong Kong Polytechnic University (GYBA6, GYL29, GYM64). 


\section{REFERENCES}

[1] Hong Kong Water Supplies Department, Voluntary Water Efficiency Labelling Scheme on Showers for Bathing(The Government of the Hong Kong Special Administrative Region, China, 2011).

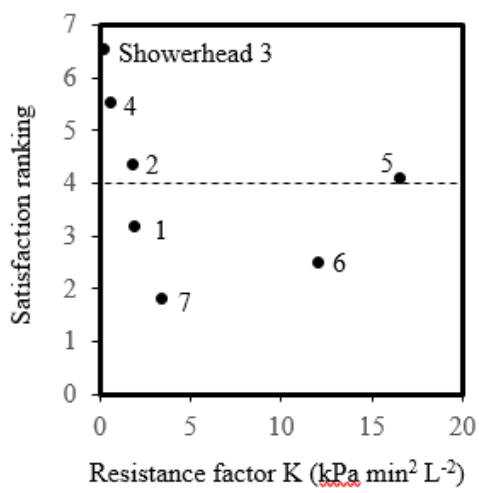

(a)

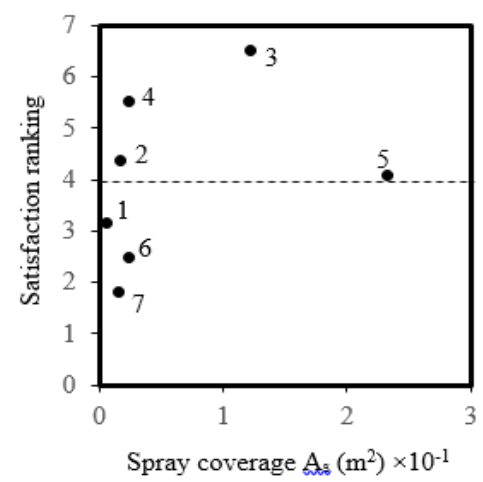

(c)

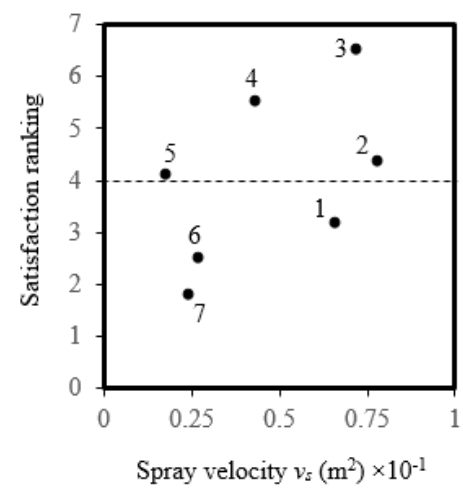

(e)
[2] M. Okamoto, M. Sato, Y. Shodai, M. Kamijo, Identifying the physical properties of showers that influence user satisfaction to aid in developing water-saving showers, Water 7, 4054-4062 (2015)..

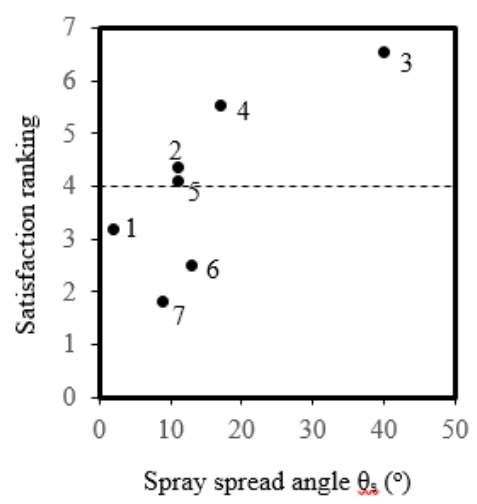

(b)

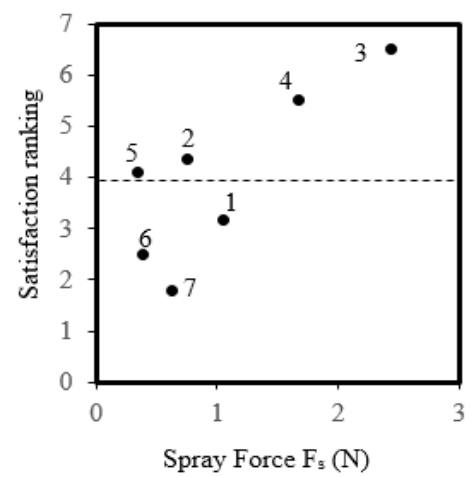

(d)

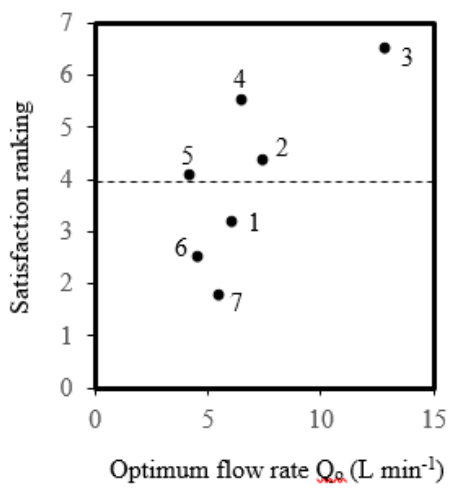

(f)

Figure 4. Relationships between satisfaction ranking, resistance factor $\mathrm{K}$ and spray properties. 